\title{
TORDAY'S PROGNOSIS FOR AGING AND MORTALITY: MORE EVOLUTION AND BETTER LIFE!
}

\author{
Kelath Murali Manoj \\ Satyamjayatu: The Science \& Ethics Foundation,Snehatheeram, Kulappully, Shoranur-2 (PO), \\ Kerala,India-679122.E-mail: satyamjayatu@yahoo.com
}

Professor of Paediatrics and Evolutionary Medicine from UCLA, John Torday, in his write-up, "Cell-Cell Communication Predicts Aging, Senescence and Death: an integrated, predictive evolutionary approach", gives us intellectually stimulating insights in this year's Biomedical Reviews (1). In the abstract, he starts off with a very emphatic tone/note- "NONE of the extant theories of aging have been effective...". This clearly portrays his view and zeal at one hand, and the importance of the agenda at hand at the other, that of a gaping lacuna in the scientific literature, to explain the inevitable "aging and death" as a part and parcel of life, and not the end of the same. Two sides of the "information quantum" coin he trades with are:

(A) Torday feels that ever since genes were discovered in the19th century, research focus/theory thereafter has always been on the idea that "genes give rise to proteins and this decides everything". He cautions that with this approach, we could lose out on several other important logics that govern life and its evolution.

(B) Citing several significant factual evidence in support of a proposal that cell-cell communication (CCC) is THE major determinant for progression in any individual life and THE core governing factor in its evolutionary history too, Torday proposes that $\mathrm{CCC}$, and not genes, is the prioritized logic that controls the "biologics" of life, including aging and death.

All this, after taking us through the roller-coaster of Lewis Carroll's literary abstractions and mysticisms of eastern religions in philosophy at one hand, AND at the other, the physical impact of "singularity and big bang" at the cosmic scale or with the chemical details of epigenesis by DNA-acetylation at the infinitesimal and the biological uni-/multi- cellular (re)productive cycle of life! Exhilarating indeed!!

It is primarily from a floating perspective that Torday's article is briefly analyzed herein. Besides the crisp pieces of deductions and elucidations he parts with through-out the write-up, the last four sections before the discussion are highly informative. Therein, Torday makes a succinct presentation of factual information on what insights CCC gives on aging, evolution and loss of homeostatic control. These are solid quanta of arguments that represent his theory $(1,2)$. The optimistic biologist posits that his CCC theory deconvolutes evolution to bring life back to the unicellular state, and not to chaos. We can see life from the way a physicist would deal with classical thermodynamics, and make analogy with Torday's theory, as shown in Figure 1. 


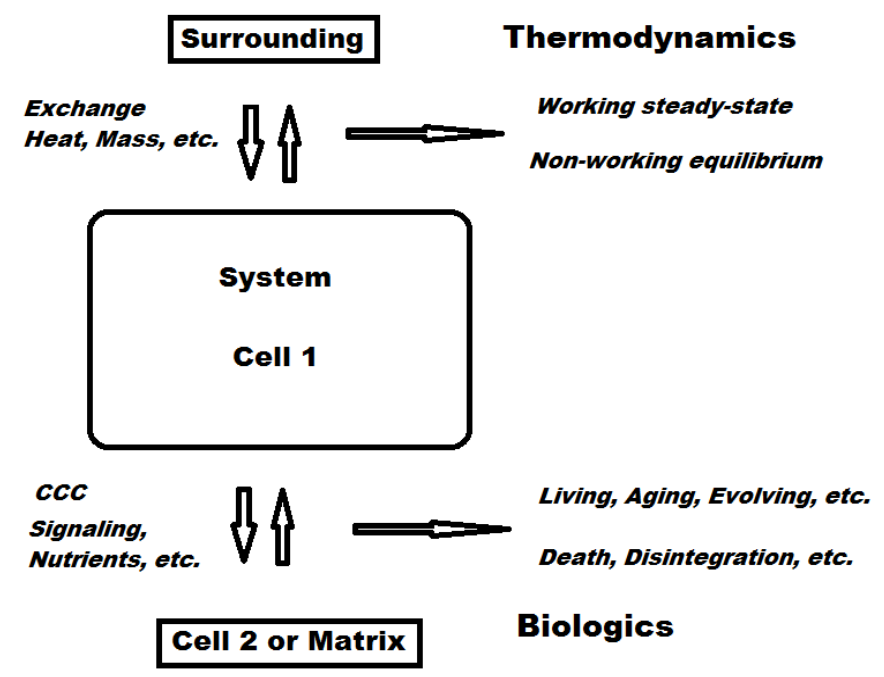

Figure 1. Drawing an analogy of Torday's CCC (Cell-Cell Communication) theory which vouches that "interactions" of the cell with its surroundings form the basis of life and all processes associated with it. This makes good analogy with treatments based in thermodynamics. The CCC theory takes away overt importance to the cell body per se and stresses on the interactions of the cell with its ambiance, primarily other cells such as itself. This theory is congenial to the functioning and evolution of multi-cellular organisms.

One "biologic" of life that CCC is not clear about is: the concept of "will or decision making". This "supramolecular intelligence" may be attributed to the central dogma that genes make proteins and their interplay control the decisions on the "long-term choices" of the cell. Also, it is not apparent how a cell could communicate with another on xenobiotics, for which neither share any evolutionary history. Further, the usage of chemiosmosis as an evolutionary principle does not appeal to this author, as it does not provide a satisfactory explanation for metabolism, cellular energetics and homeostasis along the proven principles of thermodynamics. The latter issues are addressed with murburn concept $(3,4)$.

In toto, the radiatively centrist genetic intelligence OR the directives of physiology (metabolism cum homeostasis) appear secondary, per Torday. Life, in Torday's view, has its paradigm of "birth-reproduction-aging-death" deconvoluted, to revert to unicellular stage, and into the perpetual circularity of 'cells communicating one to one'! Torday's article (1) is recommended by this author as a very interesting and informative read.

\section{REFERENCES}

1. Torday J. Cell-Cell Communication Predicts Aging, Senescence and Death: an integrated, predictive evolutionary approach. Biomed Rev 2019; 30:15-21.

2. Torday JS. A central theory of biology. Med Hypotheses 2015; 85:49-57. doi: 10.1016/j.mehy.2015.03.019

3. Manoj KM, et al. Functioning of microsomal cytochrome P450s: murburn concept explains the metabolism of xenobiotics in hepatocytes. Front Pharmacol 2016; 7:161. doi: 10.3389/fphar.2016.00161

4. Manoj KM, Bazhin N. Murburn explanation elucidates $(\mathrm{NADH}+$ oxygen + proton)'s metabolic roles in aerobic respiration, connecting it to the experimentally observed trans-membrane potential and water's homeostatic physiological function. OSF Preprints 2019, November 8. doi: 10.31219/osf.io/hx4p9 